\title{
Orientaciones para la enseñanza de la ética, el capital social y el desarrollo en las universidades latinoamericanas
}

\author{
Vallaeys, François* \\ * Profesor de la Pontificia Universidad Católica del Perú.
}

\section{Resumen}

Para lograr un verdadero desarrollo en América Latina, se requiere el fortalecimiento del capital social con la incorporación de la ética como retos teóricos y prácticos para alcanzar la eficacia. Los objetivos de este trabajo persiguen realizar una reflexión sobre los aspectos críticos que implica la voluntad de difundir la enseñanza de la ética, el capital social y el desarrollo; y plantear orientaciones pedagógicas para su enseñanza. Se discute sobre 1) la necesidad de reconocer el papel de la universidad para contribuir a mejorar la situación actual a través de la preparación de jóvenes profesionales; futuros gestores de las políticas de desarrollo del mundo, y 2) medida en que los conocimientos enseñados en las universidades reproducen las injusticias del mundo actual. En conclusión se requiere la creación de una red latinoamericana de universidades y profesores, capaces de intercambiar ideas, opiniones y experiencias, con el fin de fortalecer la propuesta de reforma de la enseñanza universitaria con relación a la ética, capital social y desarrollo.

Palabras clave: Ética, Capital Social, desarrollo, Política Educativa, América Latina.

\section{Orientations in the Teaching of Ethics, Social Capital and Development in Latin American Universities}

\begin{abstract}
In order to achieve true development in Latin America, the strengthening of social capital and its incorporation, and ethics as a theoretical and practical challenge in order to achieve efficacy, are required. The objectives of this paper are to reflect on the critical aspects that are implied by the will to disseminate the teaching of ethics, social capital and development; and to propose pedagogical orientations in their teaching. The need to recognize the role of universities in contributing to the betterment of the present situation in relation to the preparation of young professional, future managers of world development policies, and the ways in which the concepts taught in universities help to reproduce the injustices of the present world are discussed. In conclusion the creation of a
\end{abstract}


Latin American network of universities and professors capable of exchanging ideas , opinions and experiences, for the purpose of strengthening the proposed reforms in university teaching in reference to ethics, socials capital and development, is required.

Key word: Ethics, social capital, development, educational policy, Latin America.

Recibido: 02-11-29. Aceptado: 03-01-09

\section{I ntroducción}

Uno de los objetivos principales de la "INICIATIVA INTERAMERICANA DE CAPITAL SOCIAL, ÉTICA Y DESARROLLO" del Banco Interamericano de Desarrollo, es apoyar y promocionar la enseñanza del capital social y la ética aplicada al desarrollo en las universidades latinoamericanas y del Caribe. A continuación, queremos presentar, a manera de orientar el esfuerzo de las universidades y docentes comprometidos con esta inquietud fundamental de un desarrollo social y económico más ético, algunas reflexiones, análisis y sugerencias $\underline{1}$ para ayudar en la formulación de una nueva dinámica académica acerca del tema de "Etica, Capital Social y Desarrollo" utilizable para conseguir mayor lucidez y racionalidad en la formación de los futuros profesionales que tendrán a su cargo el destino de nuestra sociedad enferma de un "Mal desarrollo". Sin embargo, el mismo tema genera una serie de problemas y abarca un campo extremadamente complejo (en el sentido etimológico de lo que está tejido en conjunto). No sólo la problemática está muy sensible al conflicto de opiniones políticas e ideológicas acerca del Neoliberalismo, la Globalización y el manejo de las políticas macroeconómicas por parte de los organismos internacionales como el FMI o el Banco Mundial, invitándonos a tomar partido en el debate, sino que el mismo título de “Ética, Capital Social y desarrollo" obliga a articular ámbitos tradicionalmente separados, como aquellos de la filosofía moral, la sociología, la antropología cultural, la economía, la ecología, entre otras, lo que significa siempre un problema de trans e inter-disciplinariedad para el profesor.

Por tal motivo, nos parece importante reflexionar primero los "aspectos críticos" que implica la voluntad de difundir la enseñanza de este tema, antes que dedicarse a la concepción más precisa de un curso o un método pedagógico particular. El camino se hace al andar dice el poeta, pero los "preámbulos" permiten evitar "deambular" sin rumbo y cansar por gusto al caminante. Nos parece esencial examinar varios puntos teóricos como son: la falta de ética del desarrollo mundial actual, tanto en la práctica como a nivel de su concepción teórica; la responsabilidad de la Universidad en la permanencia y la reproducción de este modelo de "mal desarrollo" y la relación estrecha que existe entre 
crisis del paradigma dominante de la racionalidad científica y carencias éticas en los modelos de desarrollo dominantes; las carencias éticas en la formación de los estudiantes universitarios que se desprenden de esta crisis del saber y la enseñanza universitaria.

Así podremos entender que no se trata meramente de "agregar" un pequeño curso de ética y desarrollo en el curriculum universitario, sino de la posibilidad de concebir un nuevo paradigma del saber que pueda servir de eje para pensar un desarrollo económico y social más ético. El lector entenderá rápidamente que nuestro enfoque se aleja mucho de la visión común, demasiada estrecha, que concibe un curso universitario de ética pulcro y bien pensante, pero aislado en un océano de cursos que, conscientemente o no, dicen lo contrario de lo que la moral nos enseña, desde unos enfoques de racionalidad técnica, pragmática, instrumental y estratégica. Esta táctica del curso de ética como "parche" o como remedio para darle buena conciencia al decano de la Facultad de Economía o Administración, no resuelve de ninguna manera el problema. Al contrario quizás, incentiva la sensación de dicotomía entre la moral y la práctica eficaz, la ética y la ciencia, las buenas intenciones y las "buenas" estrategias, entre otras. Esta sensación de separación y oposición entre la moral y la eficacia será siempre fatal para la consolidación de las habilidades y actitudes de los estudiantes, puesto que su formación básica les insta a ser ante "profesionales eficientes y eficaces". El reto teórico y práctico es entonces de demostrar a los estudiantes que lo ético es eficaz, y que las estrategias inmorales terminan siempre siendo muy ineficientes y dañinas...".

Pero tampoco queremos caer en una visión demasiada idealista del problema, afirmando que sólo una reforma total y radical de la universidad permitiría darle el lugar que merece al enfoque de "Ética, Capital Social y Desarrollo". Si es obvio que otra sociedad, con otra forma de enseñar, tendría otro rumbo en cuanto a su desarrollo, debemos concretamente proponernos soluciones en nuestra sociedad, tal como está, con todas sus contradicciones, teniendo fe en que un grupo de profesionales y universitarios que se reúnen alrededor de una idea como la "INICIATIVA INTERAMERICANA DE CAPITAL SOCIAL, ÉTICA Y DESARROLLO" del Banco Interamericano de Desarrollo, pueden poco a poco constituir una red sólida para influir en el destino de la vida académica del continente. Se trata primero de obtener un diagnóstico consensual del problema de la enseñanza universitaria y luego de inventar soluciones adecuadas a cada realidad académica y cada país, para difundir un nuevo pensamiento acerca de lo que debe ser un "Buen Desarrollo" con "rostro humano", basado en la eficacia de la promoción del Capital social y humano.

El siguiente trabajo es un paso más hacia esta meta que, lo esperamos, podrá alimentar el debate, crear nuevos puntos de consenso y ayudar los docentes comprometidos a 
imaginar su propia manera de enseñar la Etica, el Capital Social y el Desarrollo.

\section{El "Titanic planetario" y la responsabilidad de la Universidad}

Cualquier ciudadano de buena fe que se detiene un instante para informarse acerca de la situación económica y social del mundo contemporáneo debe llegar fácilmente a la siguiente conclusión: El "Desarrollo" actual, tal como se promueve y se practica, no es ni ético, ni equitativo, ni sostenible. Esto es el paso previo a cualquier tipo de reflexión sobre la relación entre ética y desarrollo. En efecto, el docente que puede pensar que, a fin de cuentas, todo está mejor hoy día que antes, y que los problemas de pobreza y exclusión son momentáneos, como si fuera un camino obligado antes de llegar al soñado estado mundial de paz y bienestar para todos, no tiene nada que preocuparse en cuanto a la enseñanza del tema de ética, capital social y desarrollo. Su fatalismo ("siempre fue así", "no vamos a cambiar al mundo") o su "optimismo dialéctico" en cuanto a la superación final de todas las contradicciones y sufrimientos de la humanidad, gracias a una "mano invisible" que vendría siempre a armonizar los conflictos y dirigir la historia hacia la "mejor solución"르, lo dispensa de antemano de tener que criticar nada del rumbo actual de la mundialización moderna. Una sola estrategia le queda: la del laisser faire.

Pero la realidad de los hechos socioeconómicos no nos permite moralmente formar parte de esta estrategia fatalista, pasiva, y finalmente muy cínica frente a los dramas cotidianos del "mal desarrollo". El incremento de la pobreza (en más de 70 países, el ingreso per cápita es inferior hoy en día a lo que era hace 20 años), la marginación creciente incluso en los países dichos ricos (el llamado "cuarto mundo" de los países "desarrollados"), la fragmentación social y el etnocidio cultural que fragilizan el capital social de las comunidades y Estados, la contaminación ambiental como fenómeno global y crónico, las increíbles desigualdades en la distribución de los beneficios de la modernización y crecimiento, nos plantean una exigencia moral de pensar y practicar un desarrollo social y económico más ético y humano a nivel local, nacional, regional y mundial. Los pobres, los excluidos y la misma bioesfera no pueden ni deben esperar más.

Las crisis económicas, políticas, ecológicas y sociales que sacuden el mundo actual nos permiten ahorrarnos el esfuerzo de tener que justificar este diagnóstico acerca del rumbo del Desarrollo Mundial, que Morin califica de “Titanic planetario, con su «cuatrimotor» técnico, científico, económico y de beneficios, pero no controlado éticamente y políticamente"프. La problemática ética contemporánea acerca del destino de la globalización de la modernización del mundo puede formularse, según Morin, de la siguiente manera: "Hay que pensar de nuevo el desarrollo para humanizarlo. ¿Cómo 
integrar la ética? No se puede hacer una inyección de ética como se hace una inyección de vitaminas en un cuerpo enfermo. El problema de la ética es que debe encontrarse en el centro mismo de este desarrollo".

Poner la ética en el centro del desarrollo para humanizarlo es una tarea urgente que, sin duda por primera vez en la historia de la humanidad, no constituye solamente un imperativo moral, sino también una cuestión de supervivencia: No sólo es preciso pensar que el nivel actual de las desigualdades entre ricos y pobres 4 conduce, a corto o mediano plazo, a un conflicto entre la sobreabundancia del Norte y la miseria del Sur, conflicto letal por las nuevas posibilidades que nos entrega el "progreso técnico" de la industria militar moderna y el nuevo terrorismo mundial. También el mismo rumbo actual del desarrollo, concebido como crecimiento económico ilimitado, nos conduce a un callejón ecológico igualmente letal de por su "insostenibilidad" $\underline{5}$.

Existe pues una relación recíproca entre Ética / Supervivencia / Desarrollo. Pensar un nuevo Desarrollo basado en valores éticos de equidad, solidaridad, responsabilidad y sostenibilidad implica una serie de cambios en el rumbo de nuestro "Titanic planetario", como el control y la redistribución de la riqueza producida트, la superación del paradigma "hiperliberal" promovido durante las dos décadas anteriores, una nueva articulación entre desarrollo local sostenible, participación ciudadana democrática a nivel nacional y regulación global equitativa de los intercambios y del "uso" del planeta, entre otras.

La pregunta es: ¿Cómo la universidad puede contribuir a este cambio de rumbo con la preparación de jóvenes profesionales futuros gestores de las políticas de desarrollo del mundo? Para contestarla, es imprescindible empezar por reconocer el papel y la responsabilidad que tiene la Universidad en la situación actual del planeta. Sin una auténtica autocrítica y reforma del modo de pensar la formación académica, cualquier esfuerzo para promocionar la enseñanza de la "Ética, Capital Social y Desarrollo" en la Universidad terminará en el vano intento de "inyectarle ética" del exterior a una concepción universitaria del saber y de su transmisión previamente inmunizada contra cualquier curación de este tipo. No queremos decir con esto que la enseñanza impartida en nuestras universidades sea de por sí "inmoral" en cuanto se trate de desarrollo, sino que los paradigmas y hábitos que imperan en la producción y transmisión universitaria del conocimiento forman parte del proceso histórico global que permitió que nos embarcáramos en este Titanic planetario; es decir que el saber universitario, curiosamente, participa de la ceguera general.

Desde luego, nuestra tesis es que el proyecto de enseñar un nuevo desarrollo más 
humano y ético en la universidad se inscribe como parte de un esfuerzo general de fomentar mayor lucidez y responsabilidad universitaria frente a los problemas del "mal desarrollo" actual. Asimismo, implica reconocer la existencia de un problema epistemológico y pedagógico fundamental en el corazón de nuestro modelo de desarrollo dominante. Si la universidad es parte del problema actual del mal desarrollo mundial, porque es ella que ha ido formando los profesionales y responsables de las políticas macroeconómicas de desigualdad creciente de las últimas décadas, que hacen del "desarrollo" muchas veces una palabra vana o incluso, según Oswaldo de Rivero, un "mito" que conduce en realidad a los países subdesarrollados hacia un futuro de “Entidades Caóticas Ingobernables" (De Rivero, 2001), la universidad debe (moralmente) y puede (técnicamente) formar parte de la solución, formando de otro modo profesionales responsables y lúcidos para enfocar el rumbo del desarrollo hacia mayor justicia, cohesión social, capital social y crecimiento sostenible sin exclusión. En este sentido, es necesario y urgente concebir para nuestros países latinoamericanos, que sufren de un mal desarrollo crónico, una nueva manera de enseñar la economía, la administración, la política pública, los negocios, la medicina, la educación, entre otras; fundada en sólidos criterios éticos para el desarrollo y el fortalecimiento del capital social de la comunidad. Por lo tanto, a fin de que el espíritu y el objetivo de la enseñanza del tema de “Ética, Capital Social y Desarrollo" se conciba claramente, es preciso empezar por preguntar: ¿En qué medida los saberes transmitidos desde la universidad participan de y reproducen las injusticias del mundo actual?.

\section{El saber ciego y el desarrollo cojo}

La respuesta a la pregunta puede ser definida, en nuestra opinión, en el marco de los trabajos de E. Morin y la Asociación para el Pensamiento Complejo. Lo que se trata de comprender, es la relación sistémica (ecológica podríamos decir) que une: una visión estrecha y mutiladora del desarrollo económico, social y humano (el mal desarrollo actual) que conduce a las injusticias mencionadas; una lógica disyuntiva de la construcción del conocimiento, que busca simplificar permanentemente los problemas complejos y rehusa terminantemente cualquier juicio de valor en nombre de los enunciados de hechos; una fragmentación del saber científico en especializaciones y disciplinas cada vez más separadas las unas de las otras, provocando una nueva "ceguera del saber" frente a lo complejo (entretejido) de la realidad, ceguera que va reproduciendo la institución universitaria; una instrumentalización y mercantilización de la Universidad como lugar donde el cliente estudiante debe venir a buscar su futura capacidad de ser empleado por el mercado; una sociedad donde crece el individualismo, donde el individuo se "privatiza" como dice Castoriadis, entonces donde el Capital Social se hace cada vez más escaso, y la 
conciencia política se vuelve cínica; un "vacío ético" en muchas organizaciones y prácticas laborales e institucionales donde impera la mera lógica de la productividad, la racionalidad estratégica de los fines que justifican cualquier medio, y las relaciones de poder; y; una representación del conjunto social en términos de competencia permanente de todos contra todos bajo leyes darwinianas de selección natural del más fuerte.

Veamos como Morin denuncia la nueva ceguera que se apodera del saber científico, tal como se había apoderado de la institución religiosa contra la cual la ciencia moderna luch ó para salir del oscurantismo. El eje de la crítica de Morin gira alrededor de un paradigma de conocimiento basado en una lógica de la simplificación y la disyunción especializada de la realidad (Morin, 1997 y 1981). Lo que se pierde con este modelo de saber es nada menos que el derecho a reflexionar a partir de una "cultura humanista". La cultura humanista, según Morin, es la que permite interrogar al ser humano, la sociedad, su futuro, la vida y la muerte, entre otros. Es una cultura que se basa en un número de conocimientos limitado y que opera reflexiones a partir de estos conocimientos. Permite la organización de las informaciones, su accesibilidad al gran público culto, para que cada uno pueda reflexionar y meditar en base a ella. Esta cultura se queda ligada a un nivel de problemáticas de la vida común, que puede interesar a cualquiera.

Al contrario, la cultura científica, es totalmente diferente en su naturaleza. Se basa en una cantidad cada vez más enorme de informaciones que ningún espíritu humano podría memorizar. Es imposible hacerse con ella una visión del ser humano, acumulando este material cerrado, especializado, y esotérico. Es un tipo de conocimiento que el ciudadano no puede discutir, meditar, reflexionar. Es una nueva situación cultural que pone de nuevo en tela de juicio el derecho a la reflexión, y que conlleva el peligro de un nuevo oscurantismo generalizado, con sometimiento fatalista al saber esotérico de los científicos $\underline{7}$.

La nueva situación es la siguiente: Por primera vez, el saber especializado producido no lo es para ser pensado, reflexionado y discutido por seres humanos, sino para ser almacenado por instancias anónimas y manipulado por estas (ante todo los Estados y ej ércitos). De ahí que el mayor conocimiento de la realidad no corresponda ni a un mayor control y responsabilidad en el manejo de los productos de la ciencia, ni a una mayor lucidez acerca de los problemas que generan el "Progreso". El problema de la ciencia actual es que debe reintroducir al sujeto en su proceder diario, es decir poder observarse a sí misma y su papel en el conjunto de la sociedad, pero no puede hacerlo en nombre de su pretendida "objetividad". La responsabilidad, como concepto subjetivo, no tiene significado científico en el paradigma positivista de la ciencia actual, lo que podría 
conducirnos a la absurda situación de que el hecho de "ser científico" sea sinónimo de ser totalmente irresponsable en todo lo que no atañe a la pequeña porción de saber especializado de cada experto. Puesto que la relación entre Ciencia, ética y política es o bien invisible (porque negada por el principio positivista de la neutralidad axiológica de la ciencia), o bien tratada de modo indigente, la actividad científica se mutila a sí misma de su carácter humano, y termina "mutilando" a la realidad; dice Morin (1981), "Estoy cada vez más convencido, que los conceptos de los cuales nos servimos para concebir nuestra sociedad -toda sociedad- están mutilados y desembocan en acciones inevitablemente mutiladoras". Tal "mutilación" nos parece ser la verdadera causa original del mal desarrollo actual.

La Universidad es parte integrante del fenómeno en cuanto va formando a los futuros científicos haciéndoles asumir lo que Morin llama la "Escuela del duelo": Después de haberlo formado a una especialidad precisa en el seno de una Facultad con escasas relaciones con las demás, cualquier neófito ingresando a la investigación se ve obligado a renunciar al conocimiento más esencial: Se convence de que ya no se puede constituir una visión humanística global del ser humano y el mundo. Se le demuestra que el incremento informativo y la heterogeneidad de las ciencias superan toda posibilidad de síntesis. Después él se integra a un equipo de especialistas, y se ve confinado a la posesión exclusiva de un pedazo del puzzle, y empieza a "producir" conocimientos no para ser articulados y pensados, sino para ser capitalizados y vutilizados de modo anónimo. Las cuestiones fundamentales son relegadas en el discurso de opinión subjetiva, como cuestiones generales, vagas, abstractas, no operativas, entre otras. La ciencia abandona toda pregunta fundamental a los no-cientificos, pero después de haberlos descalificados a priori. Así, "el hombre se vuelve migajas" Morin (1981), y como él, el mundo está dislocado entre las ciencias, hecho pedazos entre las disciplinas, pulverizado en informaciones.

Pero Morin (1981), se pregunta si “el necesario aislamiento del objeto debe pagarse con la disyunción y la incomunicabilidad entre lo que está separado? La especialización funcional debe pagarse con una parcelarización absurda? Será necesario que el conocimiento se disloque en mil saberes ignorantes?". Para contestar a estas preguntas y hacer la ciencia consciente de su propio poder de manipulación y su manipulación por los poderes, es preciso entender que la alternativa no es: Saber especializado, preciso y limitado por un lado, e Idea general y abstracta, discurso "filosófico" (en sentido peyorativo) por el otro lado. Esta falsa alternativa es la que conduce al fracaso todos los cursos "parches" de ética, como hemos señalado, frente a los cursos especializados de economía, administración o negocios impartidos en las Facultades. La alternativa que 
Morin nos invita a pensar es aquella entre la "Escuela del duelo" y la especialización ciega por un lado, y la búsqueda de un método que pueda articular lo que está separado y ligar lo desligado, un modelo de reflexión y producción de conocimientos basado en el "pensamiento complejo", la trans e inter disciplinariedad, la vinculación entre ética y ciencia. Sólo la lucha contra la hiperespecialización ciega y la implementación en la universidad de un paradigma de ciencia más "ecológico", basado en la interrelación de los problemas y hechos en un todo irreductible y no simplificable, puede hacernos reencontrar las preocupaciones humanistas y permitir reanudar la reflexión y el debate público acerca de la ciencia.

La relación existente entre el saber hiperespecializado ciego y el mal desarrollo se vuelve evidente: Sólo en el marco de una actividad científica positivista desvinculada con la ética y la política y encerrada en los prejuicios de sus propias disyunciones y simplificaciones es posible concebir y legitimar una larga serie de instituciones y prácticas que generan el mal desarrollo actual, como por ejemplo:

1. La "economía pura", como disciplina míticamente aislada de las demás instancias sociales y la naturaleza, y encerrada en su matematización formal, sin tomar en cuenta ni la dimensión cultural, ni la dimensión ética, ni la dimensión ecológica de los fenómenos económicos, y que se transformó en el único enfoque legitimado por la ideología liberal para pensar y administrar el "desarrollo". Amartya Sen tiene que ser mencionado como el economista contemporáneo que sin duda habrá criticado de modo más agudo esta visión truncada de la economía que crea una visión mutilada del desarrollo.

2. El "tecnocratismo", que tanto en los Estados como en las Organizaciones internacionales, amenaza la misma legitimidad de la democracia en nombre del saber experto que, por supuesto, "no tiene alternativa", "es el único válido", "es racional y verdadero", luego no tiene por qué ser criticado ni fiscalizado por los electores. El dominio del experto nos invita a pensar que la política es un asunto de especialistas, que saben mejor cómo diseñar los planes de desarrollo para los ciudadanos ignorantes. Curiosamente, en nuestra época de valoración de la democracia, cobran cada vez más poder político los expertos tecnócratas no elegidos que ocupan los puestos claves en los ministerios y las instituciones internacionales.

3. Una visión macroeconómica cínica y estrecha del desarrollo en términos exclusivos de crecimiento económico, política de exportación y administración financiera de los Estados en vía de desarrollo, con todos los problemas sociales que han podido generar e incrementar las medidas de "ajuste estructural" dictados por el FMI y el Banco Mundial, limitando las compensaciones sociales a la espera del famoso "derrame" que la reactivación económica "debería” producir a favor de los sectores más pobres. 
4. La visión estrecha y parcelar de los problemas de desarrollo social, sin integración de las múltiples y entretejidas dimensiones implicadas en el cambio social, donde cada promotor social se refugia en su pequeña especialidad y los indicadores cuantitativos que puede manejar para enfrentar situaciones que los superan siempre de por su complejidad. Tales intervenciones técnicas y especializadas a menudo no toman en cuenta los aspectos humanos, culturales y cualitativos del cambio colectivo y terminan incluso a veces con crear nuevos problemas y conflictos en la comunidad.

5. La subestimación del poder del Capital social y la participación comunitaria en la solución de los problemas de desarrollo social, en nombre del saber del experto que ha podido diseñar de antemano "lo que hay que hacer", y que no busca más que "aplicar" el "programa" en una comunidad cualquiera, para una "población meta" especificada sobre el papel y definida siempre por curvas estadísticas desde su "carencia" y "vulnerabilidad". Esta visión verticalista del promotor de desarrollo experto frente a una población beneficiaria pasiva promociona en los hechos una visión del desarrollo que excluye el diálogo, la autonomía y autodeterminación, en breve que no es ética.

Desde luego, un enfoque de "Ética, Capital social y Desarrollo" no puede ahorrarse el trabajo de promoción de un nuevo modelo de saber y educación: promover un conocimiento multi e inter disciplinario, capaz de integrar en una reflexión global, compleja y responsable los datos informativos parciales y las acciones locales. Incentivar un conocimiento que pueda contextualizar sus objetos, reinscribirles en su contexto con sus retroacciones específicas, para no seguir mutilando la realidad y cegando nuestra acción sobre ella. Tal es la dimensión epistemológica y pedagógica fundamental del enfoque de "Ética, Capital social y Desarrollo": el respeto y análisis de las complejidades humanas y del mundo, sin simplificación ni reducción, para hacer entender al alumno la solidaridad sistémica intrínseca de todos los problemas de desarrollo y nuestra gran responsabilidad frente a las incertidumbres que tal complejidad no permite evitar o eludir.

\section{Miserias éticas de la Universidad y la Economía}

Según la Asociación para el Pensamiento Complejo, presidida por el mismo Edgar Morin, en su reflexión acerca de los desafíos de la Universidad del futuro $\underline{8}$, la Universidad se definió históricamente alrededor de la reivindicación de autonomía universitaria, en nombre de la neutralidad de los saberes. Decidió distinguir y separar la enseñanza en varias disciplinas en nombre de la necesaria especialización a la cual conduce la investigación. A partir del siglo XIX, se establece un especie de contrato social entre el Estado y la Universidad: "Te doy la libertad de enseñar e investigar y tú me aseguras la producción regular de la elite capaz de encargarse de los problemas de la sociedad". Pero 
hoy, este contrato social ha perdido mucha vigencia. Si sigue habiendo una pequeña elite universitaria en relación estrecha con el poder, el grueso de la población estudiantil se destina a ser los trabajadores ordinarios de la sociedad industrial y de servicios. La autonomía universitaria se volvió una ilusión frente a los grandes poderes económicos que son los únicos capaces de asegurar el futuro empleo de los egresados universitarios, e incluso, de financiar la institución misma. Y la especialización de las disciplinas es cada vez más desadaptada frente a los problemas sociales que la misma aplicación técnica de los saberes producidos por la Universidad contribuye en crear.

En este sentido, según la Asociación para el pensamiento complejo, la pregunta central es: ¿cómo concebir un nuevo contrato social entre la Universidad y la sociedad?, ¿Cómo hacer para dejar de instrumentalizar la universidad (como máquina para producir profesionales empleados por la economía) y acompañar el proceso de transmisión de conocimientos por una educación del carácter, una apertura cultural y un despertar de la responsabilidad social del estudiante? Los valores dominantes de la Universidad de hoy son: consumo, posesión, competencia, individualismo, dominación, entre otros.

Se desarrolla una Universidad de mercancía (servicio de formación al empleo del cliente estudiante) y se derrumba la Universidad como espacio público de reflexión y debate, porque esto no es rentable para la economía. "La educación esencial que la sociedad contemporánea ofrece a sus miembros, en las escuelas, los colegios y las universidades, es una educación instrumental, organizada esencialmente para aprender una ocupación profesional. Y al lado de esta educación, existe la otra, a saber las tonterías que difunde la televisión," afirma el filósofo y economista Castoriadis (1998).

Antes de descartar esta afirmación como muy exagerada, hay que analizar el contenido simbólico (y la violencia subliminal que le es asociada) que muchas publicidades para Escuelas de Negocios o carreras universitarias difunden, basado en la imagen del éxito personal de un joven ejecutivo dinámico, con corbata en el cuello y computadora en mano, y que rezan todas algo así como: “Tú quieres ganar? Te preparamos para lograr tus metas". A veces incluso, estas publicidades irresponsables utilizan explícitamente la imagen de un león corriendo detrás de una pobre cebra, para ilustrar nuestro espacio social darwiniano donde se supone que debemos pelear y correr para coger la "mejor oportunidad" entre una multitud de competidores con dientes y garras afiladas. El discurso es bien conocido; lo repite la literatura del Management permanentemente: "En nuestro mundo de cambios y progresos tecnológicos permanentes, es imprescindible adaptarse, ser flexible, creativo, para formar parte de "los primeros" y no arriesgar ser "comido" por un pez más gordo". La salvación es siempre personal (es tú oportunidad), la meta 
individualista (tú éxito), la visión a futuro consumista y hedonista (riqueza y felicidad material para tu familia).

Las nociones de beneficio social, provecho colectivo, desarrollo de la comunidad, incluso de bien público, entre otros, están sistemáticamente eludidas en el contenido simbólico de la propaganda, puesto que ésta se destina a "atraer" el "futuro cliente" para formar parte del selecto alumnado de la institución académica en cuestión que, siendo cada vez más dependiente de recursos privados propios, se ve condenada a obtener y satisfacer la mayor cantidad posible de clientes-estudiantes. Obviamente, todo el mundo se olvida de decir que a jugar al juego del "cada uno trata de ganar para sí", todo el mundo termina perdiendo. En un célebre supuesto imaginario de la teoría de los juegos, «La tragedia de las tierras comunales» Garrett Hardin (citado por Gorz, 1995) ha propuesto una pertinente crítica a las aparentes virtudes reguladoras del mercado guiado por la "mano invisible" (el cuento más preciado por los economistas liberales ortodoxos): En ese supuesto, cada campesino es libre de hacer pastar como quiera un número tan alto como sea posible de animales en las tierras comunales del pueblo. Cuando los pastos comienzan a estar sobrecargados de vacas, cada animal adicional que se introduce en ellos hace disminuir el rendimiento lechero por cabeza.

Pero esta disminución se hace a expensas de todos, mientras que cada campesino acreciente su propia producción lechera aumentando el número de sus animales. Tendrá pues interés en aumentarlo lo más rápidamente posible, más rápidamente que todos los demás, siguiendo la buena lógica de la "racionalidad" del homo economicus. La búsqueda por cada uno de su beneficio individual terminará, pues, inexorablemente, en la ruina de todos. Únicamente la limitación imperativa del número total de animales puede impedir ese desenlace: sólo un cierto control social colectivo puede permitir el desarrollo de todos.

La problemática del desarrollo social implica un modelo de juego en el cual todo el mundo puede ganar (incluso, un juego en el cual no puedo nunca ganar si tú no ganas también) y no un tipo de juego de suma nula, donde cada punto ganado por uno significa una pérdida para otro, tal como las concepciones económicas darwinianas del espacio social nos invitan a concebir. La nueva noción de Capital social nos permite lograr este cambio de perspectiva necesario para la concepción de una racionalidad del desarrollo. No sólo a través de su promoción publicitaria incentiva la Universidad, por parte del estudiante, una representación de sí mismo como un ser interesado separado de los demás, y que tiene que superarse para alcanzar el éxito personal.

Desgraciadamente, los mismos cursos y las enseñanzas impartidas en numerosos 
Facultades de Economía y Administración, Escuelas de Negocios, MBA, entre otras, promocionan una racionalidad y una actitud contraria a la ética y al espíritu del desarrollo social. El valioso testimonio del profesor Amitai Etzioni (2002) referente a su experiencia docente en la Harvard Business School (HBS) es característico del conflicto que opone la lógica de los negocios con la ética: “Una encuesta realizada en 1988 en las escuelas de negocios concluyó que sólo un tercio de los alumnos asistía a las clases de ética requeridas. En 1987, John S.R. Shad, en ese momento chairman a cargo de la Securitie and Exchange Comisión, realizó una donación personal cercana a los veinte millones de Dólares a HBS para apoyar la enseñanza de ética. El 21 de Abril de 1989, después de meses de contencioso debate, fue introducida una propuesta inicial votada por un gran número de académicos. Como profesor visitante, yo participaba como observador externo y fui testigo de una memorable escena. Las reacciones variaban desde desconfianza hasta hostilidad. Un economista argumentaba que "nosotros estamos aquí para enseñar ciencia".

Otro miembro académico quería saber "la ética de quién y que valores deberíamos enseñar" y un tercero apuntaba que los alumnos eran adultos, quienes poseían su propia educación sobre ética incorporada en sus hogares y en la I glesia. Para la finalización de la reunión, el proyecto había sido rechazado. Un miembro del Departamento de Marketing argumentó que si dicha reglamentación era implementada, su departamento debería cerrar debido a que la mayoría del contenido enseñado en dicha especialidad constituiría una forma de engaño: vender pequeños objetos en grandes cajas, introducir colores llamativos en paquetes para inducir a la gente a comprar impulsivamente y demás herramientas utilizadas. Un profesor de finanzas también estaba preocupado en relación a los efectos sobre sus enseñanzas. Los estudiantes me explicaron luego que a ellos les enseñaban como obtener ganancias a través de la ruptura de contratos impl ícitos.

En los años siguientes cursos de ética fueron enseñados en HBS, pero estos eran muy acotados, aplicando un mínimo de requerimientos para salir del paso lo más fácilmente posible. En estos días, los estudiantes toman un "mini" curso de ética obligatorio a su llegada y existe un curso de primer año llamado “Liderazgo y Comportamiento Organizacional", y eso es todo, lo mismo ocurre en otras escuelas. Un alumno de la Escuela de Negocios de Stanford, que hasta hace poco tenía un programa similar, describe su clase de ética "como ir a la Iglesia los Domingos". La visión del mundo a través de la "señal del Dólar" hace que las personas sean más cínicas. Este hecho ha sido documentado a través de datos citados en un experimento que indicaba los estándares económicos enseñados, destacando la teoría de que, cuando existe la posibilidad, la gente se comportará de forma "free ride" (sacar ventaja) y eso es la actitud "racional" según los 
economistas.

Tomemos un grupo de trabajadores donde la contribución de cada uno a una tarea específica no es posible de distinguir de la de los demás y la recompensa (digamos los aumentos de salario) está asignada igualmente entre todos. En tales condiciones, una persona racional (según el razonamiento económico) trabajará lo menos posible. En 1981, los sociólogos Gerald Marwell and Ruth E. Ames pusieron esta teoría a prueba a través de un experimento en el cual 12 grupos fueron puestos en una situación donde podían aplicar "free ride" (sacar ventaja). Miembros de 11 grupos no siguieron este comportamiento. Este no fue el caso del grupo número 12. Por qué este grupo se comportó en forma diferente? Sus miembros eran graduados en economía. Esos estudiantes estaban equivocados respecto al comportamiento de la mayoría de la gente. Pero ellos aprendieron su propia lección.

En mis propias clases de ética en HBS, los estudiantes se resistían a mi argumento respecto a que los ejecutivos deberían tomar en cuenta consideraciones éticas en sus decisiones. Ellos sostenían, de acuerdo a lo que habían sido enseñados, que una compañía focalizada enteramente en la eficiencia dejaría fuera de mercado a una segunda, mas preocupada por cuestiones éticas. La ética, según ellos me decían repetidamente, era algo que las corporaciones no podían afrontar. Solamente sí acciones morales derivan en beneficios para la corporación, con valores que pudiesen calcularse y demostrarse, la compañía debería tomar consideraciones éticas en cuenta".

Este testimonio puede parecer escalofriante a un profesor de humanidades, pero lo más escalofriante es que la mayoría de los responsables del diseño de las políticas económicas y sociales de los Estados hayan sido formados en base a esta misma racionalidad económica. A fin de cuentas, a lo que asistimos es a una autorrealización social de lo que el paradigma de la economía como ciencia positiva enseña: La sociedad se vuelve una reunión de individuos separados entre sí por conflictos de intereses, donde el más astuto gana. De ahí la integración, por parte de los alumnos, del perfil del "profesional tigre en medio de la jungla".

Lo más importante para nuestro propósito es de resaltar cómo las actitudes inmorales tienen su origen y sustento en un paradigma científico positivista y reduccionista. Razón por la cual es irrelevante querer agregar un curso de Ética en las Escuelas de Negocios y Facultades de Economía y Administración, si no se cambia profundamente la manera de definir los supuestos científicos de partida de la economía misma y la representación de la sociedad que se desprende de estos supuestos. Mientras tanto, seguirán teniendo los 
estudiantes la sensación de que ir a clase de ética es "como ir a la Iglesia los Domingos", según el interesante testimonio de Etzioni (2002).

En efecto, la tendencia en especializar (es decir separar de las demás disciplinas enfoques) y "cientificizar" (es decir formalizar y matematizar lo más que se pueda) a la economía, crea al final una especie de "economía pura" totalmente abstracta, desconectada de la realidad social, y desde luego incapaz de ser utilizada para fines de desarrollo social (Amin, 1998), cuyas características deducible de su individualismo metodológico son las siguientes:

- La sociedad se reduce a una suma de individuos meramente concebidos como homo economicus. Se ignora totalmente la sociedad real compleja con sus individuos reales complejos, tejidos en una red de relaciones sociales, religiosas, antropológicas, históricas, psicológicas, éticas, entre otras. La separación de la economía de las demás ciencias humanas es, en este sentido, desastrosa.

- A partir de esta reducción, se pretende míticamente reconstruir un equilibrio general de las relaciones económicas mediante el conjunto de las confrontaciones entre estos individuos abstractos en el mercado, suponiendo cada uno de ellos guiado por la racionalidad estratégica, calculadora e individualista. Como lo nota Etzioni (2002), curiosamente, la actitud "free ride" es efectivamente concebida aquí como "racional", aunque en la vida cotidiana de los grupos humanos, es justamente la más irracional y dañina que sea.

- La herramienta matemática es solicitada para ofrecer la posibilidad de pensar el equilibrio general (la armonización global) a partir de todas las interacciones locales. Pero necesita de la hipótesis de la "competencia perfecta" entre todos por igual, hipótesis inimaginable en la realidad. La matematización, en este caso, no sirve para conocer mejor la realidad, sino para alejarse mejor de ella, en perfecta impunidad científica.

Estas abstracciones epistemológicas tratan sistemáticamente de: simplificar la realidad humana compleja; negar las dimensiones antropológicas, culturales, afectivas, éticas, históricas, que son sin embargo centrales en la comprensión del fenómeno humano; reducir los problemas de decisión política a problemas de equilibrio sistémico por mantener. Las opciones ideológicas se esconden pues detrás de manejos casi mecánicos de cifras, curvas e índices, que, por supuesto, no se presentan como alternativas discutibles, sino como necesidad objetiva.

El paradigma de racionalidad que fundamenta todo este artificio epistemológico es aquel 
de la distinción tajante entre razón científica (objetiva) basada en constataciones de hechos y juicios descriptivos, y subjetivismo irracional de todos los juicios prescriptivos basados en valores y preferencias. Así se excluye la posibilidad de que exista una racionalidad ética, y desde luego, que la única racionalidad que queda tenga algo que ver con la ética. Por lo tanto, no es sorprendente si los colegas de Etzioni en la Harvard Business School rehusaban la idea de enseñarle ética a los estudiantes, argumentando que "nosotros estamos aquí para enseñar ciencia", que no se podía saber "la ética de quien y que valores deberíamos enseñar", o que la ética es un asunto personal que se adquiere en la familia o la Iglesia. Es obvio que si no existe ninguna racionalidad moral, la ética depende de las opciones de cada individuo o grupo, y no podemos escapar entonces del relativismo ético.

Es importante resaltar el hecho de que no sólo los presupuestos de la "economía pura", basados en el individualismo, se oponen radicalmente al fenómeno ético, basado al contrario en la solidaridad con la existencia ajena, es decir, en los fenómenos de empatía y simpatía (sentir lo mismo que el otro, querer al otro), sino también el hecho de que si la Universidad está en proceso de ser instrumentalizada (como mera herramienta para encontrar trabajo), es porque la racionalidad misma fue instrumentalizada. La raíz del problema es la misma definición de la Razón que nuestra sociedad promueve. Castoriadis (1998) denuncia el hecho de que "cada vez más, se desarrolla en el mundo occidental un tipo de individuo que ya no es más el tipo de individuo de una sociedad democrática o de una sociedad donde se puede luchar para más libertad, sino un tipo de individuo que es privatizado, encerrado en su pequeño medio personal y que se volvió cínico en relación a la política" (Castoriadis, 1998). En términos de desarrollo, significa que peligra cada vez más el Capital social de la comunidad humana, luego la capacidad de participación democrática en la gestión de la vida colectiva, y finalmente la dependencia creciente de la población frente a los sistemas de control heterónomos de la tecnocracia, los Estados y los expertos. ¿El futuro se vislumbra como una enorme maquinaria social mundial regulada por una elite de expertos científicos o queremos mantener el valor de la autonomía y la democracia, y practicarlas desde la escuela?.

Castoriadis (1998), anhela: “una reforma radical de la educación, para hacer de ella una verdadera païdaïa como decían los griegos, una païdaïa de la autonomía, una educación para la autonomía y hacia la autonomía, que conduce los que son educados -y no sólo los niños- a interrogarse constantemente para saber si actúan con conocimiento de causa en lugar de ser arrastrados por una pasión o un prejuicio". ¿Cómo concebir teóricamente este cambio, y cómo iniciar prácticamente su advenimiento, en el marco de nuestra temática de "Ética , Capital social y Desarrollo"? 


\section{Orientaciones pedagógicas para la enseñanza de la ética, el capital social y el desarrollo en las universidades latinoamericanas}

Después de haber desarrollado estos "preámbulos críticos", podemos ahora concentrarnos en el aspecto más propiamente pedagógico de la problemática.

\section{1. ¿Formación moral en la Universidad?}

La primera duda que invade el profesor frente a la problemática de la enseñanza de la ética en la Universidad, es de saber si esto sirve de algo: ¿Se puede enseñar la ética? ¿Se puede "inculcar" un comportamiento moral a los estudiantes? ¿Será útil "insertar" cursos de educación en valores en los programas universitarios?

Para contestar a estas interrogantes, es preciso notar que no se forma la personalidad moral de un individuo gracias a un curso de ética. El "Self moral" se va formando desde la pequeña infancia y se sedimenta a través de la imitación de los comportamientos adultos (los comportamientos antes que las palabras). Esto no quiere decir que ya todo esté definido para siempre cuando el estudiante ingresa a la Universidad (la condición de posibilidad de la ética es nuestra libertad y autonomía para enjuiciar, criticar y cambiar nuestros propios comportamientos), sino que existe una gran ilusión en querer implementar una "educación en valores" dentro de los programas universitarios, creyendo así poder cambiar la actitud de los alumnos, "inculcarles" el buen comportamiento y luchar así contra la "crisis de los valores".

Hay que considerar el problema de otro modo, de un modo global y complejo, sin creer poder aislar un contenido propiamente ético de la totalidad del proceso educativo universitario. Otra vez, vale la pena no simplificar el problema practicando una b́gica disyuntiva (cursos teóricos, cursos técnicos, cursos de ética) sino considerar que cualquier acto educativo tiene ya siempre de por sí una dimensión valorativa, es decir una cierta intención de promocionar (implícita o explícitamente) qué se debe y qué no se debe, qué tiene que ser valorado, qué cosa y qué actitud son legítimas y cuáles no. No se puede "insertar" valores en un programa curricular o en una institución universitaria, porque ya están desde siempre presente en la misma vida cotidiana de la institución, en la misma "transmisión" de informaciones (tanto en su forma que en su contenido). Ninguna enseñanza es axiológicamente neutral de por sí, y es un profundo error pensar que se pueda transmitir una serie de informaciones en un proceso pedagógico en forma totalmente neutral y objetiva. Por lo tanto, más útil es examinar qué valores son 
espontáneamente promovidos por el tipo de vida cotidiana, organización y enseñanza que practica una Universidad, que de querer agregarle a este conjunto (supuestamente neutral), sin reflexión previa, un curso de ética (supuestamente no neutral) cuyo contenido arriesga ser constantemente contradicho por todos los demás cursos y el mismo clima de relaciones interpersonales de la institución académica.

Lo primero es, pues, analizar qué intenciones valorativas se vinculan realmente con la práctica educativa de una casa de estudios - ¿qué contenido valorativo se esconde detrás del contenido conceptual de los cursos?-, cómo se relaciona el personal educativo con el alumnado - ¿reina el autoritarismo, el paternalismo, la democracia, la informalidad, entre otras?-, qué tipo de comunicación organizacional se privilegia - ¿la comunicación formal vertical o el libre diálogo?-, qué relación mantienen las personas con el "saber" - ¿el saber funciona como ídolo intocable o como oportunidad de pensar, reflexionar, investigar nuevos saberes?-. Practicando este "diagnóstico moral institucional”, las autoridades podrán hacer cambios organizativos muy útiles para acordar lo que se hace con lo que se pretende éticamente hacer, y así encontrar una coherencia moral en todas las dimensiones de la vida institucional (administración, organización, relaciones interpersonales, programas de enseñanza, actividades académicas y extra académicas, entre otras).

Este diagnóstico deberá incursionar en lo que se puede llamar el "curriculo oculto" de la enseñanza, hacer un verdadero análisis de los patrones morales asociados inconscientemente a la práctica docente, para así poder conocer la totalidad del proceso de formación que se imparte en la institución y no sólo su parte más visible y consciente que es la transmisión de los contenidos educativos declarados. De este modo, muchas Escuelas de Negocios o Facultades de Economía y Administración podrán reconocer que, a pesar de las buenas intenciones de su personal docente, difunden un tipo de enseñanza que invita inconscientemente su alumnado a la actitud del "free rider", y potencialmente, a ser un futuro profesional poco ético. Está demás decir que esta situación contradictoria se puede encontrar en cualquier institución universitaria, incluso las más destinadas a la promoción de una formación moral del estudiante 9 .

Después de este autoanálisis institucional, se podrá decidir si se tiene que agregar al programa de enseñanza un curso de ética o no, y con qué contenido. De modo general, podemos sugerir que la representación de la ética como algo que se tiene que "inculcar" a los alumnos de poco sirve si queremos promocionar valores democráticos de igualdad, respeto, tolerancia y autonomía. En efecto, la misma idea de inculcar presupone que el docente detiene el saber correcto de lo que se debe hacer y está legitimado para 
imponerlo a sus alumnos que, de por sí y sin su intervención, seguirían en la ignorancia de este saber moral. Estamos pues frente al modelo de la enseñanza vertical entre un maestro sabio y un alumno ignorante, criticada ya por Platón en La República. Es imposible, con este paradigma educativo, pretender después promocionar la autonomía y desarrollo personal del alumnado. Al contrario, una institución universitaria que practica, en todos los actos de su vida organizacional, el diálogo, la argumentación y el consenso, en la cual los profesores pueden ponerse de acuerdo y pasar un "contrato social universitario" con sus alumnos para decisiones acerca de la enseñanza impartida en clase, los métodos de evaluación, las responsabilidades de cada quien, las metas comunes y personales que se quiere alcanzar, entre otras; esta institución demostrará cotidianamente su valoración de la libertad, igualdad, autonomía y democracia participativa, y no necesitará un curso especial para explicar lo que ya todo el mundo sabe porque lo practica a diario.

Para formar jóvenes que sean promotores de la democracia y la cultura de paz, necesitamos de una organización escolar democrática y tolerante mucho más que de un curso sobre la tolerancia o la paz. La mejor formación ética que se le puede impartir al alumno es de permitirle ser, en el seno de su institución escolar, un ciudadano autónomo, responsable con sus pares de la elaboración, aplicación y control de las reglas colectivas de vida, después de un debate argumentativo acerca de qué reglas quieren instituir entre ellos para el provecho común. Así aprenderá el verdadero sentido de la autonomía que es el hecho de participar en la elaboración de la ley a la cual uno está sometido. Cuando habrá disfrutado de este gran placer político y entendido la dificultad y responsabilidad que esto significa, será muy improbable que después de haber salido de la Universidad, se deje embaucar por algún candidato político demagogo o pisotear sus derechos constitucionales.

Así, la formación moral en la Universidad pide el diseño de una propuesta educativa global, que cubra todos los aspectos de la vida académica y organizacional, y la mayor atención a lo que hacemos y promocionamos sin darnos cuenta, a través de nuestras actitudes, teorías y organizaciones colectivas, cuales sean nuestras buenas intenciones declaradas. Sólo la sintonía entre las informaciones y teorías transmitidas en clase, la forma de transmitirlas y la organización general de la institución donde se transmiten, asegurará una coherencia global de la enseñanza para una formación moral integral del estudiante.

Pero nuestro problema central de la enseñanza de la Ética, Capital social y Desarrollo, va más allá de esta formación moral integral, en cuanto se trata de una ética especial que 
exige un conocimiento especializado de la problemática del desarrollo social, de lo que significa Capital social, y una comparación valorativa entre diversos enfoques posibles para las políticas de desarrollo. En este sentido, nos parece imprescindible no "diluir" el problema entre varios cursos del programa curricular normal del estudiante, sino crear un curso específico que se plantee el reto de formar el alumnado a esta ética aplicada. Permitirá dedicar un tiempo propio de estudio a la dimensión moral del desarrollo, y sobre todo permitir al estudiante comparar lo que se le dice en este curso con lo que aprende en las demás materias. Las convergencias y divergencias entre ambos podrán ser motivo de debates en clase, durante los cuales los estudiantes podrán adquirir una habilidad fundamental: la de enjuiciar moralmente su propia formación universitaria, a fin de que no se trate de un aprendizaje "neutral" y pasivo, sino de la formación de un pensamiento propio a partir de las enseñanzas impartidas, con la preocupación constante por lograr mayor lucidez respecto al saber aprendido, e interrogar el valor de la enseñanza.

Desde luego, conviene examinar qué necesidades académicas particulares implica tal Ética del Desarrollo, concebida en un curso de Ética, Capital social y Desarrollo. Las dividiremos en tres clases de contenidos: conceptuales, procedimentales, y actitudinales.

\subsection{Contenidos conceptuales de un curso de Ética, Capital social y Desarrollo}

Un curso de Ética debe ante todo poder asombrar al estudiante. En efecto, lo que más se necesita en este tipo de enseñanza es poder contar con un espacio de reflexión acerca de los valores implicados en el desarrollo, un tiempo para dudar y permitirse cambiar de opinión y de visión de la problemática social. Por eso, trabajar de modo "socr ático" con los estudiantes, a fin de enjuiciar sus presupuestos, desconstruir sus prejuicios, dándoles a conocer informaciones sorprendentes para ellos, es un excelente método para despertar el interés y sobre todo la posibilidad de que vayan, cada uno por su cuenta, redefiniendo su visión del desarrollo social y de los valores y políticas que se debe promocionar para lograr los objetivos anhelados.

Al contrario de lo que comúnmente se practica, de nada sirve plantear en este curso una especie de decálogo de los valores que debe poseer el "buen gerente social", o en buen promotor de desarrollo. Primero, porque todo el mundo conoce cuáles son las buenas actitudes que debería tener en su vida diaria y profesional. Segundo, porque estas actitudes éticas son en general exigibles para cualquier persona y profesión, ya sea que se trate de un carpintero, una profesora, un economista o un gerente social. Por eso, los discursos moralistas que pretenden enseñarnos lo que ya conocemos son tan triviales y aburridos. Como lo dice el filósofo Kant en su obra maestra Crítica de la Razón práctica: 
los valores que debería practicar todo el mundo "el entendimiento más vulgar sin enseñanza" las conoce perfectamente.

Desde luego, los contenidos conceptuales de un curso de Ética, Capital social y Desarrollo no deben centrarse en explicar lo que son los valores morales, sino más bien en atacar los paradigmas comunes acerca del desarrollo (concebido como crecimiento económico y modernización) y proponer otros para reabrir las posibilidades de dudar, reflexionar y cambiar, así como promocionar la creatividad de los estudiantes para quizás plantear otros tipos de proyectos más novedosos de desarrollo, a partir de una crítica constructiva de los proyectos "fracasados".

Pero, como lo hemos visto en la primera parte de este trabajo, lo más fundamental es de inscribir este cambio de paradigma dentro de un cambio más profundo del mismo paradigma de la racionalidad y de la ciencia económica que se desprende de este.

\subsection{Cambiar de paradigma de racionalidad: razón moral y razón científica}

Como ya lo hemos mencionado, la ilusión más común acerca de la ética es de considerarla como una serie de patrones de comportamientos y valores individuales y/o colectivos que no pueden nunca ser juzgados como racionales, sino más bien como históricos, particulares a una cosmovisión cultural, y finalmente muy subjetivos. El gran problema que encontramos cuando tratamos de definir "la moral" es de saber primero si existe algo así como la Moral, como fenómeno universal y necesario en todo ser humano y grupo social, o si sólo existen reglas morales particulares, variables y relativas, en cada comunidad cultural. En este segundo caso, nos sería imposible escapar de dos escollos en la problemática ética:

1. Nos sería imposible escapar del relativismo moral, puesto que toda regla moral estaría condicionada por el sistema de creencias culturales de una comunidad humana determinada. En tal caso, la moral se entendería a lo sumo como un conjunto práctico de reglas de comportamiento internalizadas por cada individuo para asegurar la supervivencia y la cohesión del grupo social, así como la regulación y disminución de conflictos interpersonales.

2. Tal relativismo moral nos conduciría al dogmatismo moral puesto que cada moral particular no sería más que la imposición forzada de reglas relativas (es decir siempre discutibles y cambiables) a todos los miembros del grupo social. $Y$ en las condiciones actuales de mundialización de las relaciones humanas, económicas, culturales y políticas, asistiríamos a una lucha a muerte entre las diversas morales sociales, y finalmente al 
dominio mundial de la moral perteneciente a la sociedad más fuerte: iríamos del relativismo moral al dogmatismo moral, y finalmente al imperialismo moral.

Es muy útil empezar por hacer reflexionar los estudiantes acerca de las consecuencias de tal relativismo moral, haciéndoles ver que, en su vida cotidiana, ni ellos ni nadie podría mantener esta actitud relativista frente a los problemas morales: El reto es pensar en la moral como un fenómeno que se adquiere en un ámbito social y cultural particular, pero que se estructura en la persona de tal modo que supera toda particularidad social y exige el seguimiento universal de deberes supraculturales. Esto se puede entender desde la experiencia del daño moral: cuando soy víctima de un acto inmoral (agresión física y robo, entre otros), no pienso: "Esto no es lo usual en mi comunidad", "mi agresor tiene costumbres diferentes a las mías"; no considero el problema como una diferencia de opinión, de nivel educativo o de perspectiva sobre la realidad. Digo al contrario: “Esta agresión no debería ocurrir nunca", "nadie tiene derecho a hacer esto, ni conmigo, ni con los demás", "este es un acto inhumano (indigno de un ser humano)". En breve, niego terminantemente y universalmente que se pueda cometer este acto inmoral. $\mathrm{Y}$ si ocurre que me han robado o agredido en un país extranjero en el cual estoy viajando de turista, protesto de igual modo y no puedo pensar que el robo sea costumbre aceptable en este país. Desde luego, considero que convenciones sociales particulares o de las costumbres locales, sino que son universalmente conocidos y exigibles. Entonces, el profesor "socrático" puede conducir al estudiante desde la opinión común de la relatividad moral hacia la necesidad de pensar que se trata de una exigencia universal que uno debe reconocer para sí mismo y todos los dem ás seres humanos.

A partir del reconocimiento de la necesidad de una racionalidad ética universal, el profesor puede ampliar el razonamiento hacia dos perspectivas:

1. Mostrarles a los estudiantes que sólo una definición muy estrecha y dogmática de la racionalidad, concebida de modo positivista, puede prohibirle a la ética pretender a la racionalidad, a partir de la diferenciación tajante entre juicios empíricos que constatan hechos y juicios valorativos que prescriben normas, y la sistemática subvaloración de estos últimos. Al contrario, la ciencia y la epistemología contemporáneas han demostrado que no sólo la racionalidad científica no es absoluta, sino que además tampoco puede prescindir de enunciados valorativos y de normas morales fundamentales, que se practican en la comunidad de los científicos, para ponerse de acuerdo a un momento dado del avance del conocimiento científico, acerca de qué teorías, hipótesis y procedimientos de validación consideran como racionalmente válidos. Sin las normas de una ética del diálogo y la argumentación practicada entre los expertos, no sería posible establecer los 
criterios de racionalidad de la ciencia empírica $\underline{10}$. Luego, el profesor puede asombrar a sus alumnos mostrándoles que ninguna actividad científica puede prescindir de normas morales para establecerse como ciencia.

2. Examinar el contenido de una racionalidad moral universal a través, por ejemplo, de los trabajos de Kant acerca del "imperativo categórico" y el significado de una "ley moral universal". Así, el estudiante puede comprobar que es posible pensar y aplicar una especie de algoritmo moral a los problemas éticos, concebido como un principio de universalización de la intención del agente: Si tal regla de conducta puede ser universalizada (puede valer para todos), entonces es moral. Si no puede ser universalizada y al contrario se autodestruye al querer universalizarla, entonces es inmoral; por ejemplo, la mentira se autodestruye al tratar de universalizarla: Si todo el mundo se pusiera a mentir, ninguna mentira sería posible, puesto que nadie se comunicaría con nadie. También puede, gracias a la distinción kantiana entre "imperativo hipotético" (que formulan un deber condicional) e "imperativo categórico" (que formulan un deber incondicional), entender la diferencia entre las obligaciones de orden social y el deber moral: Muchos de los aparentes deberes con los que cumplimos a diario no son más que costumbres, que dependen de lo que podemos llamar la "moral social", es decir de las convenciones de nuestra comunidad, que exigen un cierto tipo de comportamiento entre sus miembros, sin poder pretender que esta exigencia sea universal.

Luego, el examen de las posibilidades y los ímites de esta racionalidad moral como principio de universalización de la regla de conducta permite entender básicamente que: La racionalidad moral del principio de universalización permite fijar el criterio para juzgar de un progreso ético en el tiempo de la cultura ética de una sociedad. Una sociedad progresa en su cultura ética si sus hábitos, leyes y convenciones se vuelven cada vez más universalizables con el paso de las generaciones; como el ámbito de la racionalidad moral concierne sólo a los deberes universalizables, queda por ende excluido de ese ámbito todo lo que se refiere a la definición de la felicidad, los hábitos culturales, las costumbres, los ritos religiosos y la vida deseable, entre otros. Nadie puede pretender universalizar su manera de valorar y definir lo que es deseable en la vida, lo que él define como la felicidad o la vida buena, exigiendo que todos los demás piensen y actúen como él. Venciendo al relativismo moral, vencemos también al dogmatismo e imperialismo moral y descubrimos una justificación racional de la tolerancia y el respeto de la alteridad cultural y social.

Otro asombro para el estudiante; sólo el más estricto universalismo moral permite asegurar el respeto a los hábitos culturales de cada comunidad humana y su autonomía en el proceso de definición de su desarrollo, evitando caer así en un etnocentrismo moral. 
Los límites de la racionalidad moral abren la posibilidad y la legitimidad de un permanente debate moral en la comunidad humana acerca de cuáles normas de vida común debemos darnos y cómo organizar nuestra sociedad. Este debate nace de los límites de la racionalidad moral (si todos los deberes pudieran ser deducidos del imperativo categórico, no tendríamos porqué debatir, sólo aplicar lo que dice la ley moral universal), pero se legitima a partir de la posibilidad de la racionalidad moral que define que el mejor argumento en el debate moral es aquél; por ejemplo, el respeto al otro y la fidelidad a la promesa son deberes éticos universales, mas no la monogamia, que sólo es una costumbre cultural que puede pretender a la mayor universalidad posible. Luego, el estudiante puede darse cuenta de la justificación racional (ética) de la democracia y el diálogo común acerca de nuestros valores y normas compartidas de vida social y política.

Llegado este punto, los estudiantes deberían tener otra visión de lo que es la racionalidad, más amplia, compleja y articulada a la comprensión de los fenómenos éticos, puesto que la ley moral no tiene nada que envidiarle a la ley de la gravedad, siendo ambas igualmente necesarias, universales y limitadas en su respectivo ámbito. Pueden ahora prepararse para reformar su visión de la economía.

\subsection{Cambiar de paradigma de "economía"}

“La filosofía, decía Merleau-Ponty, no es un cierto tipo de saber, sino la vigilancia que no nos deja olvidar el origen de todos los saberes". Nada es más útil, frente a los dramáticos problemas de desarrollo del mundo contemporáneo, que de hacer obra filosófica y volverse vigilante con los fundamentos del discurso de la ciencia económica actual. Recordar el origen del saber económico, analizar los presupuestos y axiomas de esta joven ciencia, es una tarea fundamental que permitirá al estudiante recuperar una capacidad crítica frente a un sistema de pensamiento que gobierna actualmente el mundo.

Esta tarea ya ha sido emprendida por muchos economistas, como por el famoso premio Nobel Amartya Sen, quien denuncia la lectura muy parcial que muchos economistas hacen de la obra de Smith, olvidando su especial preocupación por los asuntos éticos. Del mismo modo, Sen denuncia el individualismo metodológico de la economía pura con la figura de su homo economicus: "el hombre puramente económico es casi un retrasado mental desde el punto de vista social. La teoría económica se ha ocupado mucho de ese tonto racional arrellanado en la comodidad de su ordenamiento único de preferencias para todos los propósitos. Necesitamos una estructura más compleja para acomodar los diversos conceptos relacionados con su comportamiento" (Sen, 1986). 
La crítica al "tonto racional" de la economía clásica debe conducirnos a la promoción del enfoque de la complejidad que menciona Sen, tal como lo hemos visto en la primera parte, como el único capaz de asegurar la lucidez ética y política de los conocimientos producidos por la ciencia económica, contra todas las reducciones mutiladoras. Se trata en el curso de Ética, Capital social y Desarrollo, de ir criticando el enfoque "atomista" de la economía "pura" que, pretendiendo poder aislar una parcela estrictamente "económica" del resto de los asuntos sociales, dotada de características propias independientes de cualquier otro fenómeno, se separa de las problemáticas sociales, psicológicas, antropológicas, políticas, que se entretejen en la complejidad de la vida común humana.

El profesor podrá analizar con sus estudiantes de qué modo, a partir de una visión "cerrada" de la economía, se viene a seleccionar en la realidad sólo a los fenómenos que pueden expresarse en términos cuantitativos de valores de cambio, y que tienen la particularidad de ser autorregulables a través del mercado. Cualquier otro fenómeno se verá excluir del campo de la ciencia económica, tratando así la realidad social desde la única dimensión de la medición monetaria. El profesor recordará a los alumnos que esta selección/exclusión de los fenómenos observables es justamente la característica central de un "paradigma mental" que funciona más o menos como un "filtro" entre nosotros y la realidad.

Entre toda la amplia literatura crítica acerca de la estrechez de la visión clásica de la economía, un enfoque de Ética, Capital social y Desarrollo podrá sacar especial provecho de los aportes muy interesantes de la "economía ecológica" que decide retornar explícitamente a la definición aristotélica de economía como gestión de la casa (oikos significa el hogar, lo doméstico, en griego), considerando la casa como la totalidad del planeta (la Bioesfera). Según Jacobs (1996), esta Economía Ecológica trata de instituir una escuela de pensamiento económico donde predomine ciertos valores éticos y políticos, como son: La sostenibilidad ambiental, la redistribución justa de la renta y de la riqueza, tanto dentro de una sociedad como entre diferentes sociedades, la redistribución justa del poder especialmente a través de formas más participativas de democracia y la promoción de la diversidad cultural, la eliminación de las discriminaciones por razón de sexo, el control social de las fuerzas de mercado y el cuestionamiento del comportamiento de mercado como el único criterio de racionalidad económica, las mejoras en el bienestar definido como un desarrollo cualitativo personal y social en lugar del aumento en el consumo.

En suma, dice Aguilera (1996), “la Economía Socioecológica intenta cambiar no sólo el sistema de conocimiento sino también el propio sistema sobre el que se razona para evitar 
el reduccionismo y la parcelación practicados por el sistema de conocimiento dominante". Insistiendo sobre la relación entre práctica profesional y científica por un lado, y paradigma organizador del pensamiento por otro lado, el profesor de Ética, Capital social y Desarrollo no trata de "inculcar" a sus estudiantes una nueva ideología, sino que les entrega herramientas reflexivas para que vayan enjuiciando cualquier ideología, viendo cómo estructura y selecciona la realidad que analiza y promueve. Esto es el significado fundamental de esta "actitud de vigilancia" descrita por el filósofo Merleau-Ponty.

Obviamente, será útil estudiar cómo un cambio de paradigma económico puede cambiar todos los datos observables de la realidad. Por ejemplo, según se analice la evolución de la productividad agrícola durante el último siglo en términos clásicos de producción por hectárea, o en términos ecológicos reintroduciendo todos los costos en el cálculo de la rentabilidad energética, podemos llegar a la conclusión de que, a pesar de haberse multiplicado la productividad por hectárea en los países occidentales, la eficiencia de la agricultura ha disminuido mucho en un siglo, puesto que ha pasado de ser una agricultura básicamente solar a ser una agricultura petrolera, gastando 10 calorías de energía petrolera y química para producir 1 caloría de alimento hoy, mientras que la agricultura tradicional lograba, con la ayuda del sol, producir 10 calorías de alimento invirtiendo sólo 1 caloría de energía animal o humana (Bourg, 1996).

Estos cambios de punto de vista constituirán para el estudiante un motivo de asombro que lo preparará para reflexionar acerca de lo que significa realmente el "desarrollo".

\subsection{Cambiar de paradigma del desarrollo $\underline{11}$}

Esquemáticamente, podemos indicar aquí que la problemática pasa por cambiar de una visión social y personal de la opulencia en términos estrechos de "negocios" a una visión amplia en términos de "desarrollo". Pero se tiene que abandonar también la estrecha visión del desarrollo en términos meramente de crecimiento económico, para comprenderlo como desarrollo integral multidimensional. Otra vez aquí, Amartya Sen ha sabido, desde la economía, hacer aportes fundamentales insistiendo en el hecho de que la libertad sea el fin y el medio del desarrollo: “La expansión de la libertad es tanto el fin primordial del desarrollo como su medio principal. El desarrollo consiste en la eliminación de algunos tipos de falta de libertad que dejan a los individuos pocas opciones y escasas oportunidades para ejercer su agenda razonada. El hecho de que centremos la atención en las libertades humanas contrasta con las visiones más estrictas del desarrollo, como su identificación con el crecimiento del producto nacional bruto, con el aumento de las rentas personales, con la industrialización, con los avances tecnológicos o con la modernización 
social" (Sen, 2000).

Efectivamente, el único fin realmente universalizable del desarrollo (es decir realmente ético) es la libertad y la capacidad de conducir su vida de modo autónomo. Lo interesante de este nuevo paradigma, es que se define no de modo positivo, como la promoción de algún tipo de vida y sociedad que sería a priori deseable y que podría desde luego transformarse en modelo para todas las comunidades (lo que nos conduciría a una visión etnocéntrica del desarrollo, y al "etnocidio" de todas las culturas que no entran en el molde de la "buena manera de vivir"), sino que su Definición es más bien negativa: se trata de "eliminar algunos tipos de falta de libertad".

Este cambio de perspectiva es fundamental, en cuanto permite ya no caer más en el hechizo de la "modernización", el "progreso" y la sumisión a los "imperativos del crecimiento económico", sino más bien darnos un criterio de selección y juicio valorativo para cualquier cambio social: a saber, si se puede esperar de este cambio mayor libertad para la mayor cantidad de gente, o al contrario, nuevos sometimientos a nuevos yugos (y la modernidad produce tantos yugos como la vida tradicional). Así, otra vez, el estudiante recupera un criterio para enjuiciar la realidad de modo ético, y puede reflexionar por sí mismo acerca del valor de las políticas y programas de desarrollo social de su país. El profesor podrá ayudar el estudiante en su reflexión dándole a conocer una serie de informaciones de orden socioeconómico que le permitirá relacionar hechos aparentemente aislados y comprender la complejidad de los fenómenos de desarrollo así como de los que impiden el desarrollo. Las nociones de participación, Capital social, sociedad civil, seguridad social, transparencia de la administración pública, desarrollo sostenible, podrán ser utilizadas para organizar los múltiples aspectos de la problemática de la dinámica social. También podrán ser de mucho provecho ejemplos de desarrollo local que demuestren la posibilidad y la sensatez de otra concepción del desarrollo, más democrático, participativo, y sin embargo eficaz. No es nada inútil asombrar al estudiante mostrándole con ejemplos que la acción ética puede ser, cuando se trata de desarrollo, la más eficaz posible.

Pero todos estos contenidos conceptuales que estamos analizando deben entenderse pedagógicamente no sólo como transmisión de informaciones y nociones, sino también como promoción de nuevas habilidades intelectuales para el estudiante. Por lo tanto, todo contenido conceptual es, a la vez, un contenido "procedimental". Mientras el contenido conceptual se ocupa de lo que debe saber el estudiante, el contenido procedimental se ocupa de lo que debe hacer, sus habilidades específicas al terminar el curso (y los contenidos actitudinales de lo que debe ser el estudiante como persona). 


\section{Contenidos procedimentales de un curso de Ética, Capital social y Desarrollo}

Para poder tratar los problemas de desarrollo de modo ético, hay que desarrollar cierta habilidad técnica y estratégica en idesconfiar de la pertinencia de todas las técnicas y estrategias!, para darse la posibilidad de criticar e interrogar el valor de lo que se hace. En efecto, el enfoque de Ética, Capital social y Desarrollo nos conduce al interrogante siguiente: al hacer lo que estamos haciendo, ¿qué estamos realmente haciendo? y esta capacidad de "sospecha" necesita la práctica de ciertas habilidades por parte del estudiante, que vamos a indicar a continuación:

\subsection{Desarrollar la habilidad del estudiante para enfocar los problemas de desarrollo de modo complejo, multi, trans e inter-disciplinario}

Esta habilidad se desprende de todo lo que hemos señalado en este trabajo acerca de la dificultad de pensar la realidad del desarrollo sin mutilarla. La pregunta: "al hacer lo que hacemos, ¿qué estamos haciendo?" invita a un esfuerzo mental para reubicar nuestro actuar, siempre local, en la globalidad compleja de sus interrelaciones con las demás dimensiones de la realidad. La idea central es que el reduccionismo especializado de las teorías y de las prácticas es de por sí potencialmente antiético y siempre peligroso en lo que concierne al desarrollo social, puesto que sesga el enfoque integral requerido, deshumanizando así las acciones emprendidas.

Como lo dice Morin (1993), “Incapaz de enfocar el contexto y el complejo planetario, la inteligencia ciega se vuelve inconsciente e irresponsable. Desde ahí la necesidad ética de que el estudiante que salga de la Universidad haya integrado hábitos mentales de pensamiento complejo, multi, trans e inter-disciplinarios, para estar siempre atento a los efectos colaterales, retroacciones, consecuencias a mediano y largo plazo a nivel humano, social, económico, ecológico, entre otros, de su actuar como profesional. Esta es la habilidad primordial sin la cual es vano hablar de responsabilidad y deontología profesional. La comprensión de lo que estamos realmente haciendo (visión holística) al hacer lo que hacemos (visión especializada) necesita de esta conversión de la mente al manejo de la complejidad.

Aguilera (1996) resume las exigencias de esta habilidad: “Merece la pena insistir en que la Tierra no es la suma de un planeta físico, más la biosfera, más la humanidad. La Tierra es una totalidad compleja físico-biológica-antropológica. Debemos pensar en términos planetarios la política, la economía, la demografía, la ecología, la salvaguardia de los 
tesoros biológicos, ecológicos y culturales regionales, las diversidades animales y vegetales, las diversidades culturales. Pero no basta con inscribir todas las cosas y acontecimientos en un "marco" u "horizonte" planetario. Se trata de indagar siempre la relación de inseparabilidad y de inter-retro-acción entre todo fenómeno y su contexto, y de todo contexto con el contexto planetario.

Hay necesidad de un pensamiento que religue lo que permanece disjunto y compartimentado, que respete lo diverso sin dejar de reconocer lo uno, que intente discernir las interdependencias: un pensamiento radical (que vaya a la raíz de los problemas); un pensamiento multidimensional; un pensamiento organizador o sistémico, que conciba la relación entre el todo y las partes; un pensamiento ecologizado que en lugar de aislar el objeto de estudio lo considere en y por su relación auto-ecoorganizadora con su entorno -cultural, social, económico, político y natural; un pensamiento que conciba la ecología de la acción y la dialéctica de la acción y sea capaz de una estrategia que permita modificar o incluso anular la acción emprendida; un pensamiento que reconozca su inacabamiento y negocie con la incertidumbre, sobre todo en la acción pues no hay acción más que en lo incierto.

No se trata entonces de "agregar" una pluralidad de puntos de vista al propio de su especialidad, sino de transformar cada especialidad y disciplina de modo que sea a la vez "especializada" y humanística (en el sentido del esfuerzo de comprensión de la globalidad y la responsabilidad que implica tal comprensión). Así lograremos superar esta estúpida dicotomía entre ciencia y ética, entre pensamiento especializado y pensamiento humanístico, entre proceso analítico y proceso comprensivo, entre verdad y responsabilidad, que tanto daño ha hecho al mundo desde que la Modernidad positivista la ha instituido en todas las esferas del sistema escolar, la universidad y la sociedad.

Para acostumbrar el estudiante a este tipo de técnica de análisis complejo en la problemática del desarrollo, y demostrarle su eficacia frente a enfoques parciales y reduccionistas, el profesor tendrá a su disposición miles de ejemplos de proyectos de desarrollo fracasados por no haber tomado en cuenta, desde su diseño, las múltiples dimensiones entrelazadas de la realidad social: un ejemplo típico de ello se vio en el país africano de Burkina Faso, cuando muchas asociaciones de ayuda humanitaria, hace algunas décadas, multiplicaban las excavaciones de pozos en los pueblos de la zona árida del país, para "liberar" a las mujeres de la tarea de ir a buscar agua a kilómetros de sus viviendas. Los pobladores aceptaron, en general, de manera cortés esta ayuda del "Nassara" $\underline{12}$, y todo el mundo parecía muy contento con el pozo construido en medio del pueblo, tanto el beneficiario como el benefactor. 
Sin embargo, muchos pozos quedaron rápidamente sin uso. Parecía que los "desarrollados" no querían beneficiarse con la ayuda de los "desarrolladores". Una investigación un poco profunda logró, finalmente, encontrar el problema: el agua es cosa de mujeres en muchas etnias africanas, y el hecho de salir en grupo del pueblo a buscar agua permite a las mujeres entablar una comunicación libre, lejos del oído y la mirada inquisidora de los varones que dominan el espacio público del pueblo. El hecho de haber excavado el pozo en medio del pueblo condenaba a las mujeres a abandonar uno de los pocos espacios de libertad que tienen para intercambiar entre sí, cosa inaceptable para ellas. Por eso, ¡los pozos quedaron como recuerdos fotográficos para comprobar a la financiera europea el "buen uso" de los recursos del proyecto de..."Desarrollo"!. Este ejemplo, como otros miles $\underline{13}$, nos permite analizar la falta de ética y eficacia que condena un proceso de desarrollo definido a priori, desde el exterior, sin comprensión, ni consulta, ni participación de la población concernida, a partir de un enfoque cultural etnocentrista, para determinar lo que debe ser el "Desarrollo", lo que debe ser "lo mejor" para la población. Obviamente, el enfoque cultural del proceso de desarrollo es muy importante cuando se trata de desarrollo comunitario.

\subsection{Desarrollar su habilidad a criticar sus propios prejuicios y enfoques técnicos limitados:}

Le resultará imposible al estudiante adiestrado a pensar según los presupuestos y las estrategias de su especialidad pasar a un enfoque cultural del desarrollo si no desarrolla paralelamente la habilidad de la reflexión filosófica como asombro socrático y duda. Sin esta habilidad, es muy probable que las rutinas de su formación y su propio temor a equivocarse lo harán caer en el hechizo tecnicista del método racional único y universalmente válido para resolver los problemas.

Por lo tanto, es importante que el curso de Ética, Capital social y Desarrollo sea un real espacio filosófico socrático donde el profesor vaya incentivando la capacidad de autocrítica de los alumnos, haciéndoles reflexionar acerca de los axiomas (por definición no demostrables) de su especialidad, y cómo estos van influyendo en su interpretación de la realidad y su práctica profesional. Deconstruyendo lo que "su" ciencia haya podido construir en décadas permitirá al estudiante entenderse a sí mismo y entender mejor los límites de su especialidad, y así recuperar poder de juicio autónomo acerca de ella.

La preocupación ética es, de por sí, "asombrosa" (en sentido filosófico) puesto que pone en tela de juicio radicalmente a nuestro actuar personal y social. Las reacciones de 
defensa frente a la "angustia" del discurso moral conducen a menudo el profesional a refugiarse en su saber adquirido, legitimándose a sí mismo por la legitimidad de la racionalidad de su especialidad. Contra esta reacción, la habilidad filosófica que Sócrates había inventado, para hacer dudar de las pseudo evidencias que uno puede tener, es todavía el mejor remedio que hayamos podido encontrar. Pero el mismo Sócrates lo entendió dentro de la perspectiva de la práctica del diálogo.

\subsection{Desarrollar las capacidades del estudiante para la argumentación dialógica}

El diálogo argumentado es a la vez una técnica, una estrategia y una ética que debería practicar cualquier persona que pretende ocuparse de problemas de desarrollo. Es una técnica porque pide, por parte del estudiante, desarrollar habilidades para escuchar, expresarse racionalmente, ser interlocutor. Es una estrategia porque es la mejor solución posible para asegurarse de no reducir la realidad al enfoque estrecho de su propia interpretación parcial, para promover el Capital social dentro de la comunidad y permitir una auténtica participación ciudadana como motor de la dinámica de cambio social que un proyecto de desarrollo implica. Es también una ética, porque considerar el diálogo como un valor en sí no sólo obliga a los interlocutores al seguimiento de ciertas normas morales comunes de respeto, igualdad y co-responsabilidad, sino que también corresponde a una cierta visión del espacio sociopolítico común deseable: la democracia.

Por lo tanto, es muy útil promocionar en el curso de Ética, Capital social y Desarrollo, un espacio de debate argumentativo alrededor de problemas y dilemas específicos del desarrollo social, para que los estudiantes puedan ejercitar su juicio ético $y$, del mismo modo, comportarse como interlocutores ciudadanos democráticos. Pero es importante entender bien de qué trata la habilidad al diálogo como estrategia comunicativa específica que no debe ser confundida con otras tales como la "conversación" o la "negociación", como ocurre muy a menudo, transformando así el diálogo en una ocupación inútil o reduciéndolo a un mero instrumento para alcanzar fines propios. Veamos:

\section{a. La conversación}

Aunque aparezca como muy ligada al deseo de reconocimiento personal y la proyección de una imagen de sí, la conversación, en realidad, transmite los prejuicios sociales más que las expresiones personales. El sujeto, en la conversación, parece muy libre de decir lo que quiere a propósito de cualquier tema. Pero, sin embargo, tanto la actitud de los locutores como los temas tratados son muy limitados. Es que la función de la conversación es de resaltar la pertenencia a la comunidad, consolidar la unión colectiva (entre amigos, 
en una institución, o a nivel social en general si las personas que conversan no se conocen). Por lo tanto, todos deben ser competentes acerca del tema conversado (lo que reduce mucho los temas posibles: al final, las condiciones meteorológicas constituyen el único tema universal de conversación); y no debe producirse ningún conflicto de opinión (sino, los participantes en general se movilizan para que los pleitistas cambien de tema, o de actitud). Es así que la conversación no necesita, y no busca, una progresión en el discurso, más bien salta de un tema a otro. Es la calidad de la relación, el placer de estar juntos que importa, no tanto lo que se dice. Por eso, y para no crear conflictos, más vale decir lo que todos dicen: la conversación no dice nada nuevo, no permite crear sentido. Tampoco las palabras tienen un fin en sí mismas. Como los interlocutores están en "libertad condicional", prefieren cambiar de discurso que arriesgar un conflicto o una mala opinión de su persona. La conversación es el espacio privilegiado del reino de la opinión, no de aquel de la verdad. Se trata de pasar un "buen rato juntos", diciendo lo que todos ya han dicho mil veces, en un interminable status quo hablador.

Confundir el diálogo con la conversación hace que en el proceso pedagógico, se invite a los estudiantes para que "cada uno exprese su opinión" acerca de un tema. Las inevitables discrepancias que no tardarán en surgir se tratarán luego, al modo de la estrategia de la conversación, como diferencias de opiniones que no pueden ser resueltas, solo toleradas desde una ética "light", si se puede decir, "cada quien puede pensar lo que quiere", "todas las opiniones son válidas". De este modo, no estamos obviamente promocionando el diálogo democrático, sino la perniciosa idea relativista y cínica de que no hay verdad ni error, no hay imperativos morales ni valores, sólo hay opiniones personales. El curriculo oculto de estas prácticas pedagógicas conduce al nihilismo moral y al aburrimiento frente al debate y la comunicación, considerados al final como inútiles pérdidas de tiempo.

\section{b. La negociación}

Al contrario de la conversación, la negociación tiene un objetivo preciso, interno a la relación interlocutiva, y que va a transformar la relación misma entre los locutores: se quiere encontrar un interés común, dada la situación de que los interlocutores están en un contexto de fuerzas con posiciones diferentes y divergentes. La negociación, contra el conflicto abierto, quiere encontrar una solución, evitar la guerra. Pero el resultado de la negociación no es un consenso, sino sólo un compromiso, y con concesiones mutuas además. Lo que significa que la aceptación final es meramente formal. No satisface plenamente a nadie. Tampoco se busca la convicción de los participantes, sólo el equilibrio entre las fuerzas. Así es que el acuerdo se da por empobrecimiento de los puntos de vista de las dos partes. Esta ausencia de verdadera puesta en común enriquecedora se señala 
por el hecho de que, al terminar una negociación, se puede normalmente decidir un ganador de la negociación.

Confundir el diálogo con la negociación es reducir el debate argumentativo a una relación de fuerzas donde "ganará" aquel que habrá podido forzar su "adversario" a hacerle un máximo de concesiones a su propia "posición". Esta visión guerrera del debate suele ser muy difundida en el espacio comunicativo político contemporáneo de las contiendas con fines electorales. Las astucias sofísticas y retóricas son así confundidas con "buenos" argumentos, y el espíritu del diálogo desaparece detrás del cinismo del "gran orador".

\section{El diálogo}

En un diálogo, al contrario, no hay ganador, ni vencido. Este tipo de relación interlocutiva es muy escaso y difícil de conseguir ( pasamos la mayor parte de nuestra vida en conversaciones y negociaciones). El diálogo es exigente, implica una superación de las particularidades individuales, una conversión al ámbito de lo interpersonal. El sentido de lo que se dirá no nos pertenecerá ni a ti ni a mí, sino que el sentido se construirá entre nosotros. El resultado del diálogo es un verdadero consenso, una convicción personal y recíproca que nos supera a cada uno, puesto que los puntos de vista parciales del inicio se han enriquecido uno a otro, no por adición (mi punto de vista más el tuyo) sino por composición de un sentido nuevo a partir -y más allá- de nuestras ideas anteriores. El diálogo es el único modo de comunicación del cual puede nacer lo nuevo, la innovación, y la verdad (tanto la conversación como la negociación no se preocupan por la verdad), puesto que parte de la voluntad de una investigación, por parte de los interlocutores, siguiendo el hilo conductor de los argumentos los más racionales posible.

Pero el diálogo presupone una cierta actitud moral, aquella de la ética del argumentante: cada uno reconoce el otro como persona libre y competente, y respeta su libertad; nadie busca influenciar, seducir o manipular al otro. Ambos buscan el consenso por convicción propia libre; cada quien busca la verdad y sólo la verdad, sin consideración de intereses que disminuirían la universalidad de los argumentos encontrados; cada interlocutor reconoce la igualdad de ambos en la capacidad de encontrar juntos la verdad; ambos interlocutores se reconocen como co-responsables frente al destino del diálogo y el logro de la verdad y consenso. Nadie puede abdicar de su deber de argumentar a favor de la verdad y el consenso, para adoptar una actitud estratégica (negociación) o relativista (conversaci ón). La práctica regular, desde la pequeña infancia, en el sistema escolar como en la familia, de esta habilidad ética, es el eje verdadero de la democratización cultural de nuestra sociedad. El diálogo conduce lógicamente a la comprensión de lo ajeno. 


\subsection{Desarrollar las habilidades del estudiante para la comprensión de lo ajeno}

Desgraciadamente, el sistema escolar clásico está muy poco adaptado todavía para enfrentar los retos actuales de una intercomprensión cultural en un mundo globalizado. Obviamente, la comunicación no significa necesariamente la comprensión, y el sistema escolar no está presentemente diseñado para, más allá de la transmisión de conocimientos, asegurar una buena comprensión de lo ajeno, superando las barreras del ego, etno y socio-centrismo, así como el racismo que la Escuela democrática muchas veces no logra erradicar.

Morin (1999), señala una diferencia entre dos tipos de comprensión: La información, si es bien transmitida y comprendida, conlleva inteligibilidad, primera condición necesaria para la comprensión, pero no suficiente. Hay dos comprensiones: la comprensión intelectual u objetiva y la comprensión humana intersubjetiva. Comprender significa intelectualmente aprehender en conjunto, com-prehendere, asir en conjunto (el texto y su contexto, las partes y el todo, lo múltiple y lo individual). La comprensión intelectual pasa por la inteligibilidad. Explicar es considerar lo que hay que conocer como un objeto y aplicarle todos los medios objetivos de conocimiento. La explicación es obviamente necesaria para la comprensión intelectual u objetiva.

La comprensión humana sobrepasa la explicación. La explicación es suficiente para la comprensión intelectual u objetiva de las cosas anónimas o materiales. Es insuficiente para la comprensión humana. Esta comporta un conocimiento de sujeto a sujeto. Si veo un niño llorando, lo voy a comprender sin medir el grado de salinidad de sus lágrimas y, encontrando en mí mis angustias infantiles, lo identifico conmigo y me identifico con él. Las demás personas se perciben no sólo objetivamente, sino como otro sujeto con el cual uno se identifica y que uno identifica en sí mismo, un ego alter que se vuelve alter ego. Comprender incluye necesariamente un proceso de empatía, de identificación y de proyección. Siempre intersubjetiva, la comprensión necesita apertura, simpatía, generosidad.

Sólo un enfoque cultural del desarrollo, basado en el respeto por las características propias de una comunidad, la promoción de su Capital social a nivel horizontal (confianza y redes ciudadanas) como a nivel vertical (articulación de las redes sociales informales con la ley, los servicios públicos y el Estado), y la participación dialógica en torno al diseño y realización de los programas sociales, permitirá al estudiante del curso de Ética, Capital social y Desarrollo trabajar su capacidad de comprensión, a partir de análisis 
antropológicos que le permitirán ya no reducir el otro a ser sólo "el pobre", "el vulnerable", el "atrasado", o "la población meta". Pero la "habilidad" de la comprensión nos hace ya pasar de la problemática pedagógica de los "procedimientos" a aquella de las actitudes, lo que debe al final ya no sólo saber y hacer el estudiante, sino fundamentalmente ser.

\section{Contenidos actitudinales de un curso de Ética, Capital social y Desarrollo}

Los contenidos actitudinales son siempre los más delicados que concebir en una estrategia pedagógica universitaria. Obviamente no se trata de caer en la ilusión de que vayamos a poder cambiar radicalmente la actitud vital de una persona a través de un curso o un programa. Las revoluciones morales personales son frutos de la influencia carismática del Profeta o del Maestro más que del profesor universitario. Sin embargo, nunca están ausentes las dimensiones íntimas emocionales y afectivas en ningún curso, y menos en un curso de Ética, Capital social y Desarrollo.

La dificultad para promocionar una actitud ética preocupada por el desarrollo social común, dentro del contexto de la Universidad actual latinoamericana, es que este contexto sufre las contradicciones socioeconómicas de los países del continente. Más allá de los problemas de desaceleración de la generación de conocimiento, baja calidad del cuerpo docente, divorcio entre rutinas académicas y evoluciones sociales, que van denunciando los diagnósticos sobre la Universidad, los centros de estudios latinoamericanos (cual sea el nivel de enseñanza) reproducen la fragmentación socioeconómica de la cual sufren las sociedades víctimas del incremento de las desigualdades en las últimas décadas. Así, los colegios y universidades se transforman en ghettos, de ricos o pobres según el caso. Se incrementa cada vez más el desnivel entre educación pública y privada, y muchos de los estudiantes que acceden a las mejores universidades nunca habrán tenido una experiencia de vida con compatriotas de otras clases sociales. Esta falta de vivencia del mapa social de su país no ayuda a contrarrestar los efectos individualistas de los cantos de sirenas de la universidades que han decidido meramente preparar sus alumnos para incorporarse a un mercado laboral selecto en un entorno "darwiniano".

La fragmentación del saber que hemos denunciado corresponde también a una fragmentación social que dificulta el nacimiento de actitudes de solidaridad entre niveles socioeconómicos que nunca comunican entre ś en ningún espacio público. En este contexto adverso donde, en un país multiétnico como el Perú, uno puede aprender fácilmente a reconocer el nivel de un plantel educativo por el color de piel de sus alumnos, las buenas intenciones de la "cultura de paz" y la "igualdad democrática" tienen poca 
posibilidad de tener real efectividad. Así aumentan los riesgos de crear una nueva generación "anómica" de individuos "privatizados", sin memoria, ni espacio, ni identidad común, donde el Mercado darwiniano es el único referente de las interacciones sociales, y donde los jóvenes se culturizan a través de la integración de símbolos y valores de la industria cultural norteamericana globalizada, es decir desarraigada. Inútil de decir que el Capital social de una nación no puede sino sufrir de esta situación.

¿Cómo pueden ser creados, desde la Universidad, nuevos espacios donde se pueda dar un encuentro cara a cara entre jóvenes de medios socio-económico-culturales diferentes, y que sin embargo pertenecen a la misma "nación"? Pensemos que, en el marco de la problemática Ética, Capital social y Desarrollo, se debe alentar todas las iniciativas universitarias de "actividades de proyección social y voluntariado" para confrontar el estudiante a otra realidad y otras personas que las de su medio. No sólo sirve para prepararle como profesional, fundamentalmente puede ser la ocasión de un cambio de actitud personal y ayudar a luchar, en cierta medida, contra los efectos reproductores de los ghettos escolares y universitarios. El encuentro con el "otro" es una experiencia de vida que puede orientar el futuro profesional del estudiante, como muchos testimonios de egresados universitarios lo comprueban.

En el campo específico del desarrollo social, pasar de la teoría al trabajo de campo es una experiencia fundamental que, si es debidamente acompañada por una reflexión y una puesta en tela de juicio de sus propios prejuicios, las limitaciones de sus herramientas técnicas, y sus actitudes personales, puede conducir a los estudiantes a adquirir un poco de humildad y sentido de la importancia de la escucha, el diálogo y la participación. El propósito pedagógico ético del trabajo de campo es de ayudar el estudiante a reconocer que la actitud autoritaria tiene que ver con la ilusión de poder del experto, contra lo cual hay que desarrollar una capacidad de escucha, y de humildad: Ningún saber es neutral, ningún saber es total, y los demás también saben, son conclusiones muy valiosas que pueden surgir a partir de un encuentro cara a cara con esta población que antes existía reducida a una serie de cifras, curvas estadísticas y clichés proyectados. Al contrario, si esta experiencia de campo no es debidamente enfocada, puede muy bien terminar en "cruzada" para ir a "evangelizar" (con la buena nueva del Desarrollo y Progreso) a estas poblaciones "vulnerables" que se designan sólo por sus carencias $\underline{14}$.

Hemos hablado en otra oportunidad (Vallaeys, s/f) de las prácticas muchas veces poco éticas que se esconden detrás de las buenas intenciones del desarrollo y la ayuda humanitaria. Por eso, nos parece fundamental que las actividades de voluntariado, proyección social o trabajo de campo, que se puedan dar a nivel universitario, estén 
supervisadas y enfocadas desde la perspectiva moral, filosófica y epistemológica que hemos expuesto en el curso de Ética, Capital social y Desarrollo.

\section{A modo de Conclusión}

Quisiéramos resaltar la necesidad de consolidar, alrededor de la problemática de la enseñanza de la Ética, Capital social y Desarrollo, una Red latinoamericana de profesores e instituciones universitarias comprometidos con el tema, red que podría encontrar su espacio natural de intercambio en la plataforma virtual de la iniciativa interamericana de capital social, ética y desarrollo del BID.

El intercambio de opiniones y experiencias a través de foros virtuales, la investigación (dentro de la línea de investigación, particular énfasis debería darse para el estudio de los "currículos ocultos" de las Facultades universitarias, a fin de diagnosticar cuál es el espíritu real de las enseñanzas que se impartan a los futuros gestores de las políticas sociales y los programas de desarrollo) y difusión de materiales pedagógicos, la formación permanente de sus miembros y nuevos profesores a través de cursos de capacitación presenciales o a distancia, podrían ser tres ejes de trabajo para esta red que vayan nutriendo la propuesta de reforma de la enseñanza universitaria en el continente en dirección de la promoción del enfoque de ética, capital social y desarrollo.

\section{Notas}

1. Las mismas que son de entera responsabilidad del autor, y no necesariamente reflejan las opiniones y la política de la Iniciativa Interamericana de Capital Social, Ética y Desarrollo, ni las del BID.

2. Es muy sorprendente de ver cómo, filosóficamente hablando, el optimismo neoliberal de la "mano invisible" y del "fin de la historia" que anima el pensamiento actualmente dominante en Occidente se asemeja a lo que fue, en los países del Este el optimismo marxista de la dialéctica histórica conducente necesariamente (científicamente) hacia la superación final de las contradicciones sociales en la sociedad comunista. ¿La fe en el arreglo mágico de los problemas no sería nuestra enfermedad intelectual más contagiosa?

3. Ver Morin, Estamos en un Titanic. http:// www.iadb.org/etica.

4. “En 1960, el $20 \%$ de la población mundial viviendo en los países más ricos ten ía un ingreso 30 veces superior a aquel del 20\% viviendo en los países más pobres; en 1995 su ingreso era 82 veces superior". PNUD (1998).

5. En el marco del modo de vida moderno actual, elevar el nivel de vida de la población del Perú hasta aquel del 
promedio de los norteamericanos significaría contaminar 400 veces más el país de los Incas! El crecimiento económico anhelado en los términos tradicionales del desarrollo, es en realidad insostenible para el planeta.

6. Como por ejemplo la propuesta del economista americano James TOBIN, premio Nobel de economía, de gravar con un impuesto las transacciones especulativas en el mercado de divisas. Incluso con un gravamen particularmente bajo del $0,1 \%$, el impuesto Tobin proporcionaría cerca de 100.000 millones de dólares al año, suma que podría ser destinada al desarrollo social y humano de los más necesitados.

7. El nuevo oscurantismo viene del hecho de que el principio de disyunción o separación instituye una inteligencia ciega que destruye lo complejo, aísla los objetos de su ambiente, no puede concebir los lazos observador/observado. Las realidades claves pasan luego desapercibidas en los hiatos que separan a las disciplinas científicas y universitarias. Es lo que le pasa actualmente al fenómeno "Desarrollo", despedazado entre economía, administración, antropología, sociología, educación, medicina, ingenierías de todo tipo, entre otras.

8. Ver Les défis de I'Université du futur, Association pour la Pensée Complexe.

9. Un colega profesor de Teología me contaba recientemente cómo ciertos de sus alumnos futuros sacerdotes hacían trampa durante los exámenes escondiendo papelitos con los apuntes del curso en su Biblia.

10. Ver los trabajos de Popper, Habermas, Apel sobre la doble racionalidad de las ciencias empíricas y de la "razón comunicativa".

11. No insistiremos, en este punto, en la crítica al modelo actual de desarrollo y el planteamiento de alternativas, porque la literatura es muy extensa sobre el tema, y cada profesor podrá elegir la perspectiva que más le parece conveniente. Un buen punto de partida panorámico, sin embargo, podrá ser el artículo de Kliksberg (2002) “10 falacias sobre los problemas económicos y sociales de América Latina", en su libro Hacia una economía con rostro humano, LUZ-OPSU, Maracaibo.

12. Término con el cual los mossi (etnia mayoritaria de Burkina Faso) denominan al hombre blanco, desde el tiempo de la colonia.

13. En el Perú, existen ejemplos similares en relación con la implementación de letrinas y viviendas en zonas campesinas andinas, sin cuidado de su articulación con la cosmovisión tradicional de la población.

14. Hace poco tiempo, una muy famosa institución caritativa lanzó en el Perú una campaña de colecta de dinero con un afiche representando la foto de un pequeño niño indígena selvático, acompañada con este sintomático texto: “Su cuerpo y su alma están vacíos...jllénalos!". 


\section{Bibliografía Citada}

1. Aguilera, F. (1996), La economía ecológica como un sistema diferente de conocimiento, Ponencia presentada en la XXII Reunión de Estudios Regionales. EI desarrollo de las regiones. Nuevos escenarios y perspectivas de análisis. Pamplona, 20-22 de Noviembre.

2. Amin, Samir (1998), “L'Economie "pure", nouvelle sorcellerie", Le Monde diplomatique, Agosto. Paris.

3. Amitai Etzioni (2002), "Cuando se trata de ética, las escuelas de negocios reprueban". The Washington Post, 4 de Agosto. USA.

4. Bourg, D (1996), Les scénarios de I'écologie, Hachette, París.

5. Castoriadis, C. (1998), Le Monde Diplomatique. Francia.

6. De Rivero, Oswaldo (2001), El Mito del Desarrollo. Fondo de Cultura Económica, Lima, Perú.

7. Gorz (1995), Metamorfosis del trabajo, Sistema, Madrid.

8. Jacobs, M. (1996), "What is socio-ecological economics?" En The ecological economics bulletin, Vol.1, N. 2.

9. Morin, Edgar (1999), Los siete saberes necesarios para la educación del futuro, UNESCO.

10. Morin, Edgar (1997), Introducción al Pensamiento complejo. Gedisa, Barcelona.

11. Morin, Edgar (1993), “El desafío de la globalidad", En Archipiélago, N. 16, pp. 6674).

12. Morin, Edgar (1981), EI método 1. La naturaleza de la naturaleza, Cátedra, Madrid.

13. PNUD (1998), I nforme Mundial sobre Desarrollo Humano de 1998. 
14. Sen, Amartya (2000), Desarrollo y libertad, Planeta, Barcelona.

15. Sen, Amartya (1986), Los tontos racionales: una crítica de los fundamentos conductistas de la teoría económica, Filosofía y Teoría Económica, Fondo de Cultura Económica. México.

16. Vallaeys, F. (s/f), "El difícil camino hacia un desarrollo social ético", http:// www.iadb. organización/etica. 